\title{
Mental healthcare in South Korea
}

\author{
Guk-Hee Suh
}

Associate Professor of Psychiatry, Hallym University College of Medicine, Seoul, Republic of Korea; Visiting Lecturer, Imperial College School of Medicine, London, UK, email: suhgh@chol.com

Contributions to

the country profile section are

welcome: please contact Shekhar

Saxena (email: saxenas@who.int)

\begin{abstract}
Te Korean peninsula is located between China and Japan. After the Second World War, the Republic of Korea was established in the southern half of the Korean peninsula. South Korea has a total area of $98480 \mathrm{~km}^{2}$ and a population of 48598175 (July 2004 estimate). The per capita gross domestic product (GDP), in terms of purchasing power parity, is U S\$17 700 (2003 estimate) (Central Intelligence Agency, 2004). The illiteracy rate (among those aged over 15 years) is $1.9 \%$ ( $0.7 \%$ for males and $3 \%$ for females) (2003 estimate). Life expectancy at birth is 75.6 years (72.0 years for males and 79.5 years for females) and the infant mortality rate is 7.2 per 1000 births (2004 estimate). The unemployment rate is $3.4 \%$ (2003 estimate). The proportion of the population aged 65 and over is currently 8.7\% (2004 estimate) (Korea N ational Statistics Office, 2003). O ver $40 \%$ of the total Korean population (i.e. some 20 million) lives in Seoul and its vicinity. South Korea is highly urbanised and modernised. Besides central government, local government is based on seven metropolitan cities and nine provinces.
\end{abstract}

\section{Mental health services}

There is one hospital bed for every 148 citizens and one psychiatric bed for every 1446 . There is one physician for 830 citizens and one psychiatrist for every 19500 (2002 estimates).
The basic healthcare needs of the Korean population are covered by universal public health insurance, funded by premiums, not taxes. This is compulsory, and there is no private health insurance. $\mathrm{N}$ one the less, the private sector accounts for approximately $90 \%$ of mental health services, as there are too few public facilities. However, the government is responsible for free nationwide healthcare funded by taxes for the poor and aged. Thanks to an active community mental health movement in the public and private sector of psychiatry, since 1995, 242 public health centres nationwide have registered to take care of people with mental illness, including elderly people with dementia or stroke. In 2002, there were 989 specialist mental health facilities in South Korea: 46 community mental health centres, 66 social rehabilitation facilities, 74 mental hospitals, 207 general hospitals with psychiatric out-patient departments, 541 psychiatric clinics and 55 nursing homes.

Table 1 shows the progress in the public mental health project run by the Korean government. Both community and institutional care programmes provide long-term care. Home help services and delivered meals, adult day care, short-stay and respite care and a visiting nursing programme are also available to people with mental illnesses, including elderly people with a mental disability. Table 1 shows that care capacity is being substantially increased. The proportion of the population in need of community care who could be catered for by the maximum community care capacity will increase from $4.7 \%$ in 2003 to $72.2 \%$ in 2011 , and the equivalent

Table 1. Projected estimates of the provision for community and institutional mental healthcare in Korea

\begin{tabular}{|c|c|c|c|c|c|}
\hline Year & 2003 & 2005 & 2007 & 2009 & 2011 \\
\hline \multicolumn{6}{|l|}{ Community care } \\
\hline Number of home help centres & 120 & 470 & 1020 & 1770 & 2769 \\
\hline Number of day care centres & 166 & 416 & 866 & 1516 & 2561 \\
\hline Number of short-term care centres & 32 & 131 & 356 & 681 & 1079 \\
\hline Total number of community care facilities & 318 & 1017 & 2242 & 3967 & 6409 \\
\hline M aximum community care capacity, $n$ & 15200 & 52700 & 114700 & 200700 & 319930 \\
\hline Number of patients who need community care & 320974 & 353080 & 387528 & 416319 & 442925 \\
\hline Community care capacity rate $(\%)$ & 4.7 & 14.9 & 29.6 & 48.2 & 72.2 \\
\hline \multicolumn{6}{|l|}{ Institutional care } \\
\hline Number of residential homes (capacity) & $161(11270)$ & $245(17150)$ & $325(22750)$ & $405(28350)$ & $488(34160)$ \\
\hline Number of nursing homes (capacity) & $120(8400)$ & $192(13440)$ & $264(18480)$ & $355(24850)$ & $454(31780)$ \\
\hline Number of dementia care hospitals (capacity) & 37 (3 852) & 51 (4 952) & $65(6052)$ & 79 (7 152) & $93(8252)$ \\
\hline Total number of institutional care facilities & 318 & 488 & 654 & 839 & 1035 \\
\hline Maximum institutional care capacity & 23522 & 35542 & 47282 & 60352 & 74192 \\
\hline Number of patients who need institutional care & 77836 & 84838 & 92347 & 98624 & 104423 \\
\hline Institutional care capacity rate (\%) & 30.2 & 41.9 & 51.2 & 61.2 & 71.0 \\
\hline
\end{tabular}

Source: Ministry of Health and Welfare (2003, personal communication). 
proportion of those in need of institutional care from $30.2 \%$ in 2003 to $71.0 \%$ in 2011 (see Table 1).

To meet the demand for institutional care arising from the increasing numbers of cases of dementia and stroke, special units in nursing homes and dementia care hospitals are being constructed all over South Korea.

A multidisciplinary community-oriented approach has been adopted and close working relationships have been maintained with vario us professionals caring for people with mental illnesses. In general, each team has a catchment population of about 50000-200 000, which would include some 3500-14 000 people aged 65 and over. The staff usually comprise one consultant psychiatrist (generally part-time), one community psychiatric nurse, one social worker or psychologist and several volunteers. They draw on a variety of community resources in devising the most effective care pathway for people with mental illnesses and focus on enabling them to stay longer in their own homes. They have responsibility for registration, case management and education. Some of them run day care programmes for schizophrenia, alcohol dependence or dementia. The public sector has been more active in home-visiting outreach activities, while the private sector has been promoting day care rehabilitation. These movements in South Korea have been instrumental in developing infrastructure and providing mental health services.

\section{Psychiatric treatments}

The predominance of the private sector and the relatively generous reimbursement of public health insurance have made Korea a large and early market for novel drugs in psychiatry, although reimbursement for novel drugs has now become subject to much stricter regulation. Atypical antipsychotics and novel antidepressants are much more widely used in South Korea than are traditional antipsychotics and tricyclic antidepressants. Electroconvulsive therapy also has been frequently used; there is no special limitation on its use. Psychoanalysis, psychodynamic psychotherapy, cognitive- behavioural therapy, group therapy and even hypnosis are applied on in-patient wards and out-patient clinics in psychiatry.

\section{Training}

Basic undergraduate training in psychiatry forms part of the curriculum in medical school. Postgraduate training comprises a 4-year residency in psychiatry, in which both the theoretical and the clinical aspects of psychiatry are covered. This leads to the psychiatric board examination. Training programmes are accredited under the auspices of the Korean $\mathrm{N}$ europsychiatric Association, which is also the medical body that deals with all academic issues.

\section{Epidemiological issues}

There have been several community-based epidemiological studies on the prevalence of mental disorder in South Korea (Cho et al, 1998; Suh et al, 1999a, 2003;
Suh \& Shah, 2001). Epidemiological data on the prevalence of mental health problems help to determine the need for care. Dementia and depression are the most common mental disorders and the most severe public health problem, especially in the older population. Korean reports have been comparable to those of Western studies. Suh et al (2003) interviewed 1037 people aged 65 and over, and found a prevalence of dementia of $6.6 \%$ (Alzheimer's disease $4.2 \%$, vascular dementia $2.4 \%$ ). A nationwide survey examined the prevalence of depressive symptoms in the Korean population. The prevalence rates using a cut-off score of 16/17 on the CES-D (Center for the Epidemiologic Study of Depression) scale were $23.1 \%$ of male adults, $27.4 \%$ of female adults and $24.3 \%$ of the elderly population (Cho et al, 1998; Suh et al, 1999a). A community-based survey reported a prevalence of 'the wish to die' within last 2 weeks among elderly respondents of $14.6 \%$ (Suh et al, 1999b).

A total of 788000 persons, equivalent to $21 \%$ of the South Korean elderly population, were in need of long-term care in 2001. Of these, at least 74000 needed institutional care, while the remainder required community care. The number of patients with dementia and disturbed instrumental activities of daily living has been estimated at 186000 , and this group will require institutional care at some point (Sunwoo, 2001).

\section{Problems in mental healthcare in South Korea}

There are several problems in mental healthcare in South Korea. First, medical, psychiatric and social welfare services are separate, which means that integrated care is not available. This separation originated from an artificial distinction between 'treatment' and 'care'. Second, subacute care facilities are too scanty: there are generally only acute care and chronic care facilities. Differentiation of function in facilities is necessary, for example 'hostel' for mild cases and 'nursing home' for severe cases. Third, public care facilities are too few (less than $10 \%$ of the overall mental healthcare provision). M ost facilities are private and this leads to frequent conflict between consumers, government and suppliers. However, the Korean government has substantially increased its expenditure on healthcare and social welfare to meet the unmet need. It is also actively considering the adoption of a long-term care insurance system, similar to those that have been adopted in Germany and Japan.

\section{Conclusion}

The private sector provides approximately $90 \%$ of mental health services in South Korea. These services are in short supply for the population, despite the relatively high number of psychiatrists. Thanks to an active community mental health movement in the public and private sectors of psychiatry and the long-term care plan being implemented by the Ministry of $\mathrm{H}$ ealth and Welfare, better care provision is expected. Although services have
To meet the demand for institutional care arising from the

increasing

numbers of cases

of dementia and

stroke, special

units in nursing

homes and

dementia care

hospitals are

being constructed

all over South

Korea.

Medical,

psychiatric and

social welfare

services are

separate, which

means that

integrated care is not available. This

separation

originated from an artificial

distinction between

'treatment' and 'care'. 
actively been trying to move away from institutionalisation to community-based care, the inadequate number of fully qualified community mental health professionals, prejudice towards mental illnesses among the general population and less active participation of board-certified psychiatrists make this move difficult. H owever, a large investment in infrastructure, the development of programmes for community care, upgraded training and active research will lead to a more modern, communitybased, multidisciplinary approach to healthcare in So uth Korea.

\section{References}

Central Intelligence Agency (2004) World Factbook. Available at www.cia.gov/cia/publications/factbook/geos/ks.html. Last accessed 22 N ovember 2004.
Cho, M. J., Nam, J. J. \& Suh, G. H. (1998) Prevalence of symptoms of depression in a nationwide sample of Korean adults. Psychiatry Research, 81, 341-352.

Korea N ational Statistics O ffice (2003) Statistical Annual 2002. Daejeon: Korea $\mathrm{N}$ ational Statistics $\mathrm{O}$ ffice.

Suh, G. H. \& Shah, A. (2001) A review of the epidemiological transition in dementia - cross-national comparisons of the indices related to Alzheimer's disease and vascular dementia. Acta Psychiatrica Scandinavica, 104, 4-11.

Suh, G. H., Cho, D. Y., Rhoo, I. K., et al (1999a) Prevalence and risk factors of depressive symptomatology among the Korean elderly. Journal of the Korean Geriatrics Society, 2, 49-60.

Suh, G. H., Kim, J. K., Jung, Y. J., et al (1999b) Wish to die and associated factors in the rural elderly. Journal of Korean Geriatric Psychiatry, 3, 70-77.

Suh, G. H., Kim, J. K. \& Cho, M. J. (2003) Community study of dementia in the older Korean rural population. Australia and $\mathrm{New} Z$ Zealand Journal of Psychiatry, 37, 606-612.

Sunw00, D. (2001) Survey of the Long-Term Care Service Need of Old Persons and Policy Direction. Seoul: Korean Institute for $H$ ealth and Social Affairs.
Only recently has

Romania tried to add community

mental healthcare services to the traditional system of active

psychiatric

hospital care. This started by radically reducing the number of beds, but unfortunately without ensuring adequate community care programmes and services.

\title{
Psychiatry and geriatric psychiatry in Romania
}

\author{
Nicoleta Tataru
}

Senior Consultant Psychiatrist, Oradea, Romania, email: nicoleta tataru@hotmail.com; President of the Romanian Association of Geriatric Psychiatry, Member of the Honorary Board of the Romanian Association of Psychiatry, and Member of the Board of the International Psychogeriatric Association and of the Association of European Psychiatrists

omania is now in a period of transition from communism to democracy. Geographically, Romania, like other Eastern European countries, is on the border between the Western world and the Middle East and Asia; until December 1989 it was behind the 'Iron Curtain'.

It covers $237500 \mathrm{~km}^{2}$, divided into 42 districts. In 2002 it had a population estimated to be 21795000 . The unemployment rate was $10.5 \%$. Fourteen per cent of the general population were over the age of 65 . The infant death rate was 17.3 per 1000 and life expectancy at birth was 67.6 years for males and 71.1 years for females. The gross domestic product per capita (GDP) expressed in purchasing power parity (PPP) is US\$6041, and total health expenditure is $2.60 \%$ of GDP. The proportion of the national budget spent on the health system is $4 \%$, and around $2 \%$ of the total health budget is for mental health. There are 189 physicians per 100000 population.

\section{Mental health services}

$\mathrm{N}$ ationally, there are 908 psychiatrists (4.16 per 100000 population), of whom 260 are child psychiatrists (1.19 per 100000 population). They all work in the public health sector, although some also work in private ambulatory clinics. There are also psychologists and social workers in the mental healthcare system.

Most psychiatric services are provided by hospitals and out-patient clinics attached to the Ministry of $\mathrm{H}$ ealth. There are 38 psychiatric hospitals and many psychiatric departments in the general hospitals (a total of 17079 beds) as well as day hospitals (1222 beds) to care for patients with both acute and chronic mental illnesses; in addition there are 166 beds for patients with drug dependency. There are also 65 mental health centres for adults and children with mental illness. There are no private psychiatric hospitals.

The special needs of people with mental illness have not always been recognised and respected by the generic health services. However, a mental health law was passed in Romania only in August 2002 (Monitorul oficial al Romaniei, XIV, 589). This was the first step towards reform of the mental health services and care system. In chapter 4 of the law, the forms of specific mental health services existing in Romania are listed, along with care standards for people with mental disorders. O nly recently has Romania tried to add community mental healthcare services to the traditional system of active psychiatric hospital care. This started by radically reducing the number of beds, but unfortunately without ensuring adequate community care programmes and services. Many long-stay psychiatric wards were transferred to the 